\title{
Features of engineering surveys for recreational facilities construction in high-mountain environment
}

\author{
Olga Krinochkina ${ }^{1, *}$ and Andrey Lavrusevich ${ }^{1}$ \\ ${ }^{1}$ Moscow State University of Civil Engineering, Yaroslavskoye sh. 29, 129337 Moscow, Russia
}

\begin{abstract}
This article discusses the features of engineering surveys for recreational facilities construction in the high-mountain environment. Basic survey types are considered. Special attention is paid to danger geological processes and phenomena, and the condition of basic components of mountainous landscape for the planned recreational facilities. The study is intended for construction designers, ecologists, geologists and surveyors. Key words: engineering survey, geodesy, dangerous geological processes, recreational facilities, high-mountain environment.
\end{abstract}

The features of an engineering survey will be considered by the example of surveys conducted under the supervision of the authors in the valley of rivers Mamisondon and Adaikom, North Ossetia - Republic of North Ossetia-Alania, for construction of the Mamison mountain and sports recreational facilities. The engineering survey included all the known basic types: engineering geodetic, engineering geological surveys (EGS) and engineering ecological surveys (EES). This study discusses the features of the latter.

The engineering surveys for construction of the Mamison mountain and sports recreational facilities were carried out in compliance with the Russian regulatory documents in force.

Development of high-mountain areas for recreational purposes is quite a new trend resulting from the rising interest of modern recreation lovers to extreme sports and ecotourism.

Engineering surveys (ES) carried out for construction of recreational facilities (RF) in the high-mountain environment should consider the features involved. First, this is explained by the special status of recreation areas, and, second, by the very high-mountain environment. These conditions predetermine the high dynamics of all processes, both geotechnical and geochemical, which, in their turn, condition the features of geotechnical and ecological surveys. See below for more details.

The status of a recreation area implies a presence of corresponding potential, i.e. such an area should contain recreation resources. The latter firstly indicate the components of natural environment of proper quality. And it's the components of the environment constituting part of recreation resources that we will focus on.

Construction of recreational facilities requires the presence of a few natural factors, namely: aero-, hydro-, phyto- and certainly lithocomponents. These form peculiar

\footnotetext{
*Corresponding author: vdovinaok@mail.ru
} 
mountanious landscapes being most valuable targets of recreational nature management [1]. So, the challenge of an ecological survey is to determine if the quality of these natural components meets sanitary standards. Besides, their geochemical situation is also important for recreation areas [2, 3]. High-mountain areas are considered a priori clean since all longlivers of the planet usually live there. Yet, local communities for the lives of many generations tend to adapt to the local geochemical situation, so even considerably exceeded concentrations of harmful substances in the components of the environment over the maximum permissible thresholds are not detrimental to them. However, it was A.P. Vinogradov who found that even relatively small concentrations of some elements (2-3 times the Clarke values) could cause serious diseases [4]. This is why a geoecological assessment of a recreational area should consider its potential for causing ecological and geochemical danger to the environment conditioned by the area geochemical situation. The latter is usually determined by the peculiarity of the chemical composition of bedrock. Mountanious areas may contain low thickness or no loose sediments often resulting in bedrock outcropping. The high content of toxic elements could make them accumulate in depositing components of the landscape. A potential natural environmental and geochemical danger (NED) is estimated by the total accumulation of chemical elements of Danger Classes 1-3, the level of which exceeds the Clarke values considerably [5].

Apparently, the feature of an ecological survey for RF construction planning is assessment of the NED of the lithological component of the recreational resources within the area.

The other afore-mentioned feature of engineering surveys for recreational facilities construction in the high-mountain environment deals with the highland itself and refers to a geotechnical survey. The latter should consist in a more detailed study of dangerous geological processes (DGPs) and phenomena because these are highly intensive in the highlands environment [6].

Since elevations at the RF under study vary from 2,000 to $3,800 \mathrm{~m}$, there is every ground to relate it to highlands. High intensity of DGPs is observed here emphasizing the importance of ensuring safety of the facility units.

The technique of investigating DGPs in the course of EGS, at the stage of the investment feasibility study for the Mamison mountain and sports recreational facilities, also had some peculiarities.

First of all, a 1:25,000 preliminary sketch map of Quaternary sediments was generated after data gathering and summarizing, and based on satellite image interpretation and remote sensing. During the map compilation, special attention was paid to identification of basic genetic types of DGPs based on their final result - occurrence of corresponding accumulations and analysis of the degree of their activity from the point of morphological features, terrain fragmentation degree and other attributes.

Upon verification of the interpretation results with a reconnaissance survey, the final Quaternary sediments map was generated, the analysis of which revealed some patterns of DGPs occurring at the planned construction site.

For example, a pattern of activation of exogenic processes was identified related to erosional network development and a decrease of erosional bases in Holocene period, to neotectonic factors and high seismicity within the Nar zone.

Note that the river valleys forming the basin of river Mamisondon are deeply cut into the slopes of ridges Bokovoy and Glavny preserving their U-shapes at the tops and having a complex structure of glacial, sloping and alluvial-proluvial accumulations. All these disperse sediments are the material of collapses, mudflows and landslides under certain conditions. The latter are most common at the area under study. 
Landslides are contributed by the widely spread Jurassic clayey rocks and periodic overwetting of this material. The neotectonic factor is also important being expressed in the intense fragmentation of rocks in thin zones of most recent tectonic movements.

The field study revealed that there were 2 types of landslides based on the composition of displaced masses: deluvial and structural gravitational.

The deluvial landslides comprise deluvial loam consisting of abundant fine and coarse crushed bedrock. These are individual landslide bodies not widely spread within the area.

Besides the loose deluvial sediments, the structural gravitational landslides are composed of lumps and piles of bedrock crushed to blocks displaced downslope, along with the deluvial rocks. Based on the results of natural observations, largest landslides of type ES were mapped.

Some of the landslides were related to the Upper Quaternary quiet stabilized landslides, the movements of which are not known.

In order to consider the geodynamic and technical condition of mudflow catchment areas, we made a qualitative assessment of the area by the degree of modern erosional fragmentation of the basins of tributaries of river Mamisondon. It was found that, from the point of mudflow danger, the territory of the basins of rivers Adaikom and Mamisondon could be assigned a medium danger level. Mudflows with a simultaneous efflux of hard material under $50,000 \mathrm{~m}^{3}$ are observed here.

It was also found that the mudflow origination centers developed at $>2,300-2,500 \mathrm{~m}$ elevations, so all basins of the main tributaries may be considered potentially mudflow danger. The study results were used in the identification of zones of DGPs requiring safety measures to be taken during the construction of the facility units.

In consideration of the ecological survey at the high-mountain areas to be developed for recreational purposes, it is worth restating that their specificity consists in assessment of the natural environmental and geochemical danger (NED) of the landscape components. In order to assess it quantitatively, I.A. Morozova suggested using a natural environmental danger index $[7,8]$. It was calculated by analogy with the cumulative pollution index (CPI) of Ye.Yu. Sayet [9] and characterizes the effect of a group of toxic elements Classes 1-3 of Danger at the sampling point.

It is calculated by the following formula:

$$
\mathrm{NED}=\sum \mathrm{Cc}-(\mathrm{n}-1),
$$

whereKk - the Clarke value of concentrations, $\mathrm{n}$ - number of chemical elements with $\mathrm{Cc}>1\left(\mathrm{Cc}=\mathrm{C}_{\mathrm{f}} / \mathrm{C}\right)$.

$\mathrm{C}_{\mathbf{f}}-$ situation content of chemical element (Danger Classes 1-3), C - the Clarke values for global soils.

Note that, approbation of this index should involve rationing (normalization) of bedrock to the Clarke values for the crust (C) per Bowen [10], and the Clarke values for global soils should be used for rationing of bottom sediments. The $\mathrm{Cc}$ value we used exceeded 2 since, in abruptly changing high-mountain conditions, $\mathrm{Cc} \leq 2$ reflects fluctuations of natural situation. Besides, sampling average $\left(\mathrm{C}_{\mathrm{av}}\right)$ should be used instead of $\mathrm{C}_{\mathbf{f}}$.

By analogy with CPI [9] and depending on the NED value, the areas under study were related to those of medium danger (8-16), danger (16-32) or highly danger $(>32)$ pollution levels; we have also introduced a permissible pollution level $(<8)$.

Then, the territory was zoned based on the nature management restriction for recreation arrangement. The basin-landscape concept developed by S.V. Zotov was used as the basis [11]. Unlike in the concept, the zoning criteria laid in the level of NED and geodynamic conditions within the basins (see Table 1). It was determined using a two-point system: 
strained (if at least one of the DGPs occurs within the basin) and unstrained (if only stabilized DGPs occur or are absent within the basin).

Thus, the main features of engineering surveys at the stage of the investment feasibility study for the recreational facilities construction in the high-mountain environment are associated with arrangement of geotechnical and ecological surveys. For the first group, they consist in more detailed investigation of DGPs both during the preparation (applying satellite image interpretation and remote sensing), and the fieldwork period; for the second group - in assessment of NED components of the survey area landscape.

Table 1. Zoning of the territory by level of NED and geodynamic conditions.

\begin{tabular}{|c|c|c|c|c|c|c|}
\hline \multirow[b]{3}{*}{$\begin{array}{l}\text { Seq. } \\
\text { No. }\end{array}$} & \multirow[b]{3}{*}{ Basin } & \multicolumn{4}{|c|}{ Zoning criteria } & \multirow[b]{3}{*}{ Regulation type and recommendations } \\
\hline & & \multirow[b]{2}{*}{ 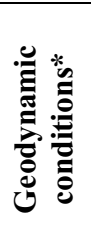 } & \multicolumn{3}{|c|}{ NED } & \\
\hline & & & $\begin{array}{l}\stackrel{\infty}{v} \\
\text { त्र }\end{array}$ & 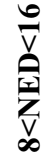 & 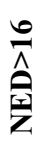 & \\
\hline 1 & Gibitandon & - & + & - & - & No limitations \\
\hline 2 & Kozydon & + & + & - & - & No limitations \\
\hline 3 & Zemegondon & - & + & + & - & $\begin{array}{l}\text { Limited regulation for using materials } \\
\text { within } 8<\mathrm{NED}<16 \text { areas }\end{array}$ \\
\hline 4 & $\begin{array}{l}\text { Ruchatdon- } \\
\text { Bubudon }\end{array}$ & + & + & - & - & No limitations \\
\hline 5 & $\begin{array}{l}\text { Upper } \\
\text { Mamison }\end{array}$ & + & + & + & - & $\begin{array}{l}\text { Limited regulation for using materials } \\
\text { within } 8<\mathrm{NED}<16 \text { areas }\end{array}$ \\
\hline 6 & Lagatkom & + & - & + & + & $\begin{array}{l}\text { Completely limited use of materials within } \\
\text { NED }>16 \text { areas. Limited regulation for } \\
\text { using materials within } 8<\mathrm{NED}<16 \text { areas. } \\
\text { Surface water microcomponent } \\
\text { composition quality control }\end{array}$ \\
\hline 7 & Kaitakomdon & + & + & - & - & No limitations \\
\hline 8 & Kasaikomdon & + & + & + & - & $\begin{array}{l}\text { Limited regulation for using materials } \\
\text { within } 8<\mathrm{NED}<16 \text { areas }\end{array}$ \\
\hline 9 & Khalatsa & + & + & - & - & $\begin{array}{l}\text { Surface water microcomponent } \\
\text { composition quality control }\left(\mathrm{NH}^{+}{ }_{4}\right)\end{array}$ \\
\hline 10 & $\begin{array}{l}\text { Kuatedon- } \\
\text { Retsidon }\end{array}$ & + & - & + & + & $\begin{array}{l}\text { Completely limited use of materials within } \\
\text { NED }>16 \text { areas. Limited regulation for } \\
\text { using materials within } 8<\mathrm{NED}<16 \text { areas. } \\
\text { Surface water microcomponent } \\
\text { composition quality control }\end{array}$ \\
\hline 11 & Dnuidon & - & - & + & + & same \\
\hline 12 & Adaikom & + & - & + & + & same \\
\hline 13 & Tib-Tsargas & + & - & + & + & same \\
\hline 14 & Pus & + & - & + & + & $\begin{array}{l}\text { Completely limited use of materials within } \\
\text { NED }>16 \text { areas. Limited regulation for } \\
\text { using materials within } 8<\mathrm{NED}<16 \text { areas. } \\
\text { Surface water microcomponent } \\
\text { composition quality control }\end{array}$ \\
\hline
\end{tabular}

*Geodynamic conditions: + strained, - unstrained. 


\section{References}

1. Federal Law On Natural Healing Resources, Health-Improving Areas and Resorts, No.26-FZ, dated February 23 (1995)

2. O.K. Vdovina, A.A. Lavrusevich, R.V. Vysokinskaya, I.M. Evgrafova, K.S. Polyakova, MGSU Bulletin 8, 98-106 (2014)

3. O.K. Vdovina, Ye.N. Malinina, A.N. Popova, Subsoil Exploration and Preservation 7, (2012)

4. A.P. Vinogradov, Proceedings of the USSR Academy of Sciences 18(4/5), 283-286 (1938)

5. O.K. Vdovina, Bulletin of the Peoples' Friendship University of Russia. The Engineering Studies series 3, (2009)

6. V.L. Poznanin, O.K. Vdovina, Subsoil Exploration and Preservation 9-10, 139-142 (2006)

7. I.A. Morozova, Geochemical Landscapes and Environmental Threat, The Applied Geochemistry collection, 1 edition. Geochemical Mapping (IMGRE, Moscow, 2000)

8. I.A. Morozova, Subsoil Exploration and Preservation, 29-30 (1994)

9. Yu.Ye. Sayet, B.A. Revich, Ye.P. Yanin et al., The Environmental Geochemistry (Nedra Publishers, Moscow, 1990)

10. H.J.M. Bowen, The Environmental Chemistry of the Elements (Academic Press., London-New-York-Toronto-Sydney-San Francisco, 1979)

11. Proceedings of the USSR Academy of Sciences, the Geography series 6, 55-65 (1992) 